\title{
Meso-Microscale Study of Glycerol/Dodecanol Pickering Emulsions Stabilized by Polystyrene-Grafted Silica Nanoparticles for Interfacial Catalysis
}

Guolin Zhao, ${ }^{\mathrm{a}, \mathrm{b}}$ Bing Hong, ${ }^{\mathrm{b}}$ Bo Bao, ${ }^{\mathrm{a}}$ Shuangliang Zhao, ${ }^{\mathrm{a},{ }^{*}}$ and Marc Pera-Titus ${ }^{b, *}$

${ }^{1}$ State Key Laboratory of Chemical Engineering and School of Chemical Engineering, East China University of Science and Technology, Shanghai 200237, China

${ }^{2}$ Eco-Efficient Products and Processes Laboratory (E2P2L), UMI 3464 CNRS - Solvay, 3966 Jin Du Road, Xin Zhuang Ind. Zone, 201108 Shanghai, China

*Corresponding authors: szhao@ecust.edu.cn (SZ), marc.pera-titus-ext@solvay.com (MP)

\section{SIMULATION DETAILS: DISSIPATIVE PARTICLE DYNAMICS (DPD)}

Dissipative particle dynamics (DPD) is a coarse-grained simulation method that preserves the essential properties of matter while simplifying the freedom of the system. Therefore, research on large-scale systems has better applicability than other simulation methods. In DPD simulations, the bead motion is described by the Newton's equation of motion. The external force $\left(\mathbf{F}_{\mathbf{i}}\right)$ of each bead is composed of three components: conservative force $\left(\mathbf{F}_{\mathbf{i j}}{ }^{\mathbf{C}}\right)$, dissipative force $\left(\mathbf{F}_{\mathbf{i j}} \mathbf{D}\right)$, and random force $\left(\mathbf{F}_{\mathbf{i j}} \mathbf{R}^{\mathbf{1}}{ }^{1-3}\right.$

$$
\mathbf{F}_{i}=\sum_{i \neq j}\left(\mathbf{F}_{i j}{ }^{C}+\mathbf{F}_{i j}{ }^{D}+\mathbf{F}_{i j}{ }^{R}\right)
$$

The three different component forces represent different contributions of the system. Firstly, the conservative force $\left(\mathbf{F}_{\mathrm{ij}}{ }^{\mathbf{C}}\right)$ is expressed by the contribution of the soft interaction force, and is also the primary force over the bead. This force can be accounted by the expression

$$
\mathbf{F}_{i j}{ }^{C}=\left\{\begin{array}{cl}
a_{i j}\left(1-r_{i j} / r_{c}\right) \hat{\mathbf{r}}_{i j} & r_{i j}<r_{c} \\
0 & r_{i j} \geq r_{c}
\end{array},\right.
$$

where $r_{i j}=r_{i}-r_{j}$ is the centroid distance between the $i^{t h}$ and $j^{t h}$ beads, $\hat{\mathbf{r}}_{\mathbf{i j}}=r_{i j} /\left|r_{i j}\right|$ is the unit vector of the direction from the $i^{\text {th }}$ to the $j^{\text {th }}$ bead, $r_{C}$ is the cut-off radius of the pairwise bead interaction, setting the basic length-scale in DPD simulations, and the coefficient $a_{i j}$ represent the maximum repulsion between two interacting beads. When $i$ equals to $j$, the interaction parameter of $a_{i i}$ can be expressed as follows ${ }^{4}$ 


$$
a_{i i}=\frac{75 k_{B} T}{\rho}
$$

where $\rho$ is the bead number density, $k_{B}$ is the Boltzmann constant and $T$ is the absolute temperature. $k_{B} T$ represents the reduced energy in DPD simulations, and is set to 1 . When the bead number density of the system is 3 , the intra-species interactions $\left(a_{i i}\right)$ is 25 . In parallel, the inter-species interaction parameters $\left(a_{i j}\right)$ can be calculated from the Flory-Huggins binary interaction parameters $\left(\chi_{i j}\right)$ as a function of $\rho^{4}$

$$
\begin{array}{ll}
\Delta a_{i j}=a_{i j}-a_{i i}=\chi_{i j} / 0.286 & \left(\rho r_{c}^{3}=3\right) ; \\
\Delta a_{i j}=a_{i j}-a_{i i}=\chi_{i j} / 0.689 & \left(\rho r_{c}^{3}=5\right) .
\end{array}
$$

The Flory-Huggins parameters can be computed from the Hansen solubility parameters ${ }^{5}$ using the expressions

$$
\begin{aligned}
& \chi_{i j}(T)=\frac{V_{i j}}{R T}\left[\delta_{i}(T)-\delta_{j}(T)\right]^{2}, \\
& \delta_{i}^{2}=\delta_{i, d}^{2}+\delta_{i, p}^{2}+\delta_{i, h b}^{2} .
\end{aligned}
$$

where $\delta_{i}$ is the Hansen solubility parameter, and $\delta_{i, d}, \delta_{i, d}$, and $\delta_{i, d h}$ represent the dispersion, polar, and hydrogen-bonding components, $V_{i j}$ is the partial molar volume of the DPD bead, and $R$ is the constant of perfect gases.

In addition to the conservative force, the dissipative force $\left(\mathbf{F}_{\mathbf{i j}}{ }^{\mathbf{D}}\right)$ and the random force $\left(\mathbf{F}_{\mathrm{ii}} \mathbf{R}^{\mathbf{R}}\right)$ represent the viscosity contribution and the thermal fluctuation contribution of system, respectively. These forces can be expressed as follows

$$
\begin{aligned}
& \mathbf{F}_{i j}{ }^{D}=-\eta \omega^{D}\left(r_{i j}\right)\left(\hat{\mathbf{r}}_{i j} \cdot \mathbf{v}_{i j}\right) \hat{\mathbf{r}}_{i j} \\
& \mathbf{F}_{i j}{ }^{R}=\sigma \omega^{R}\left(r_{i j}\right) \xi_{i j} \Delta t^{-1 / 2} \hat{r}_{i j} .
\end{aligned}
$$

where $\eta$ is the friction coefficient, $\boldsymbol{v}_{i j}=\boldsymbol{v}_{\boldsymbol{i}}-\boldsymbol{v}_{\boldsymbol{j}}$ is the relative velocity between the $i^{\text {th }}$ and $j^{\text {th }}$ beads, $\boldsymbol{\sigma}$ is the amplitude of noise, $\xi_{i j}$ is a random number with a zero mean and unit variance with a the Gaussian distribution, $\Delta t$ is the time step, and $w^{D}\left(r_{i j}\right)$ and $w^{R}\left(r_{i j}\right)$ are the weight functions for dissipative and random forces, which are related by the expression

$$
\omega^{D}\left(r_{i j}\right)=\left[\omega^{R}\left(r_{i j}\right)\right]^{2}=\left\{\begin{array}{cc}
\left(1-\frac{r_{i j}}{r_{c}}\right)^{2} ; & r_{i j}<r_{c} . \\
0 ; & r_{i j} \geq r_{c}
\end{array}\right.
$$




$$
\sigma=\sqrt{2 \eta k_{B} T}
$$

Along this work, we used reduced DPD units to boost the calculations. In particular, we used $r_{C}$ and $k_{B} T$ as length and energy units, respectively. Besides, the mass of the beads, $m$, was set equal to 1 . In this study, $r_{c}$ was set to $7.11 \AA$.

\section{$\underline{\text { References }}$}

1. Groot, R. D.; Warren, P. B. Dissipative Particle Dynamics: Bridging the Gap Between Atomistic and Mesoscopic Simulation. J. Chem. Phys. 1997, 107, 4423-4435.

2. Español, P. Dissipative Particle Dynamics Revisited. In Challenges in Molecular Simulations; Mac Kernan, D., Ed.; European Science Foundation: France, 2002; Vol .4, chapter III, pp. 5977.

3. Shi, K-H.; Lian, C.; Bai, Z-S.; Zhao, S-L.; Liu, H-L. Dissipative Particle Dynamics Study of the Water/Benzene/Caprolactam System in the Absence or Presence of Non-ionic Surfactants. Chem. Eng. Sci. 2015, 122, 185-196.

4. Maiti, A.; McGrother, S. Bead-Bead Interaction Parameters in Dissipative Particle Dynamics: Relation to Bead-Size, Solubility Parameter, and Surface Tension. J. Chem. Phys. 2004, 120, 1594-1601.

5. Hansen, C. M. Hansen Solubility Parameters: A User's Handbook, CRC Press, Boca Raton, $2^{\text {nd }}$ edition, 2000. 


\section{FIGURES}

Figure S1. Evolution of $\left|\left(\gamma_{\mathrm{SG}}-\gamma_{\mathrm{SD}}\right)_{\mathrm{C}}\right|(\mathrm{A})$ and $\mathrm{E}_{\mathrm{p} \text {,dim }}(\mathrm{B})$ as a function of the sulfonation degree and distribution of sulfonic acid groups for a planar surface. Chain length: $N=5(A 1, A 2)$ and $N=20$ (B1, B2). The red-solid, blue-dotted and green-dashed curves refer to top, uniform and bottom distribution of sulfonic acid groups, respectively. Surface densities of sulfonated PS and $\mathrm{SiOH}$ groups were kept at 1.0 and 2.8 groups $/ \mathrm{nm}^{2}$, respectively

Figure S2. Local concentration profiles (Z-averaged) of (A) polystyrene (PS) and $\mathrm{SO}_{3} \mathrm{H}(\mathrm{SH})$ moieties, (B) G and (C) D along the Y-direction from the grafted SiNPs surface for the glycerol (A1, B1, C1) and dodecanol (A2, B2, C2) phases. NPs: N=10, top distribution of sulfonic acid groups, variable sulfonation degree at 0\% (black-solid), 40\% (red-dashed), 80\% (blue-dashed) and $100 \%$ (green-dotted). Surface densities of sulfonated PS and SiOH groups were kept constant at 1.0 groups $/ \mathrm{nm}^{2}$ and 2.8 groups $/ \mathrm{nm}^{2}$, respectively.

Figure S3. Local concentration profiles (Z-averaged) of (A) polystyrene (PS) and $\mathrm{SO}_{3} \mathrm{H}(\mathrm{SH})$ moieties, (B) $\mathrm{G}$ and (C) D along the Y-direction from the grafted NPs surface for the glycerol (A1, B1, C1) and dodecanol (A2, B2, C2) phases. NPs: N=10, bottom distribution of sulfonic acid groups, variable sulfonation degree at $0 \%$ (black-solid), 40\% (red-dashed), $80 \%$ (bluedashed) and 100\% (green-dotted). Surface densities of sulfonated PS and SiOH groups were kept constant at 1.0 groups $/ \mathrm{nm}^{2}$ and 2.8 groups $/ \mathrm{nm}^{2}$, respectively.

Figure S4. Local concentration profiles (Z-averaged) of (A) polystyrene (PS) and $\mathrm{SO}_{3} \mathrm{H}(\mathrm{SH})$ moieties, (B) $G$ and (C) D along the Y-direction for the glycerol (A1, B1, C1) and dodecanol (A2, B2, C2) phases. NPs: $\mathrm{N}=30$, uniform distribution of sulfonic acid groups, variable sulfonation degree at $0 \%$ (black-solid), $40 \%$ (red-dashed), $80 \%$ (blue-dashed) and $100 \%$ (greendotted). Surface densities of sulfonated PS and $\mathrm{SiOH}$ groups were kept constant at 1.0 groups $/ \mathrm{nm}^{2}$ and 2.8 groups $/ \mathrm{nm}^{2}$, respectively.

Figure S5. Local concentration profiles (Z-averaged) of (A) polystyrene (PS) and $\mathrm{SO}_{3} \mathrm{H}(\mathrm{SH})$ moieties, (B) G and (C) D along the Y-direction for the glycerol (A1, B1, C1) and dodecanol (A2, B2, C2) phases. NPs: $\mathrm{N}=30$, bottom distribution of sulfonic acid groups, variable sulfonation degree at 0\% (black-solid), 40\% (red-dashed), 80\% (blue-dashed) and 100\% (greendotted). Surface densities of sulfonated PS and $\mathrm{SiOH}$ groups were kept constant at 1.0 groups $/ \mathrm{nm}^{2}$ and 2.8 groups $/ \mathrm{nm}^{2}$, respectively.

Figure S6. Local concentration profiles (Z-averaged) of (A) polystyrene (PS) and $\mathrm{SO}_{3} \mathrm{H}(\mathrm{SH})$ moieties, (B) G and (C) D along the Y-direction for the glycerol (A1, B1, C1) and dodecanol (A2, B2, C2) phases. NPs: $\mathrm{N}=30$, top distribution of sulfonic acid groups, $0.25 \mathrm{PS}$ groups $/ \mathrm{nm}^{2}$, variable sulfonation degree at $0 \%$ (black-solid), $40 \%$ (red-dashed), 80\% (blue-dashed) and 100\% (green-dotted).

Figure S7. Local concentration profiles (Z-averaged) of (A) polystyrene (PS) and $\mathrm{SO}_{3} \mathrm{H}(\mathrm{SH})$ moieties, (B) G and (C) D along the Y-direction for the glycerol (A1, B1, C1) and dodecanol (A2, B2, C2) phases. NPs: $\mathrm{N}=30$, top distribution of sulfonic acid groups, 0.50 PS groups $/ \mathrm{nm}^{2}$, variable sulfonation degree at $0 \%$ (black-solid), $40 \%$ (red-dashed), 80\% (blue-dashed) and 100\% (green-dotted).

Figure S8. Local concentration profiles (Z-averaged) of (A) polystyrene (PS) and $\mathrm{SO}_{3} \mathrm{H}(\mathrm{SH})$ moieties, (B) G and (C) D along the Y-direction for the glycerol (A1, B1, C1) and dodecanol (A2, B2, C2) phases. NPs: $\mathrm{N}=30$, top distribution of sulfonic acid groups, 0.75 PS groups $/ \mathrm{nm}^{2}$, 
variable sulfonation degree at $0 \%$ (black-solid), $40 \%$ (red-dashed), $80 \%$ (blue-dashed) and 100\% (green-dotted).

Figure S9. Local concentration profiles of G (red) and D (blue) in the bulk phase along the Zdirection.

Figure S10. (A) Snapshot of the G (red), D (blue-pink) and G-D (bright green-bright blue) equilibrium distribution at the surface of a sulfonated PS-grafted NPs (PS, green; $\mathrm{SO}_{3} \mathrm{H}$, yellow); Local concentration profiles (Z-averaged) of (A) G, (B) D and (C) G-D along the Y-direction for the glycerol (A1, B1, C1) and dodecanol (A2, B2, C2) phases at variable G-D concentration of 1\% (red-dashed) and 5\% (blue-dashed) and 10\% (green-dotted). NPs: N=10, top distribution of sulfonic acid groups, 20\% sulfonation degree. Surface densities of sulfonated PS and $\mathrm{SiOH}$ groups were kept constant at 1.0 groups $/ \mathrm{nm}^{2}$ and 2.8 groups $/ \mathrm{nm}^{2}$, respectively.

Figure S11. Local concentration profiles (Z-averaged) of (A) G, (B) D and (C) G-D along the Ydirection for the glycerol (A1, B1, C1) and dodecanol (A2, B2, C2) phases at variable G-D concentration of 1\% (red-dashed) and 5\% (blue-dashed) and 10\% (green-dotted). NPs: N=10, top distribution of sulfonic acid groups, $60 \%$ sulfonation degree. Surface densities of sulfonated PS and $\mathrm{SiOH}$ groups were kept constant at 1.0 groups $/ \mathrm{nm}^{2}$ and 2.8 groups $/ \mathrm{nm}^{2}$, respectively.

Figure S12. (A) Snapshot of the G (red), D (blue-pink) and G-D (bright green-bright blue) equilibrium distribution at the surface of a sulfonated PS-grafted NPs (PS, green; $\mathrm{SO}_{3} \mathrm{H}$, yellow); Local concentration profiles (Z-averaged) of (A) G, (B) D and (C) G-D along the Y-direction for the glycerol (A1, B1, C1) and dodecanol (A2, B2, C2) phases at variable G-D concentration of $1 \%$ (red-dashed) and 5\% (blue-dashed) and 10\% (green-dotted). NPs: N=30, top distribution of sulfonic acid groups, 20\% sulfonation degree. Surface densities of sulfonated PS and $\mathrm{SiOH}$ groups were kept constant at 1.0 groups $/ \mathrm{nm}^{2}$ and 2.8 groups $/ \mathrm{nm}^{2}$, respectively.

Figure S13. Local concentration profiles (Z-averaged) of (A) G, (B) D and (C) G-D along the Ydirection for the glycerol (A1, B1, C1) and dodecanol (A2, B2, C2) phases at variable G-D concentration of $1 \%$ (red-dashed) and 5\% (blue-dashed) and 10\% (green-dotted). NPs: N=30, top distribution of sulfonic acid groups, $60 \%$ sulfonation degree. Surface densities of sulfonated PS and $\mathrm{SiOH}$ groups were kept constant at 1.0 groups $/ \mathrm{nm}^{2}$ and 2.8 groups $/ \mathrm{nm}^{2}$, respectively.

Figure S14. Snapshot of the G (red), D (blue-pink) and G-D (bright green-bright blue) initial distribution at the surface of a sulfonated PS-grafted NPs (PS, green; $\mathrm{SO}_{3} \mathrm{H}$, yellow) with $40 \%$ sulfonation degree and top distribution of sulfonic acid groups. (A1) $\mathrm{N}=10,0 \% \mathrm{G}-\mathrm{D}$ concentration, (A2) $\mathrm{N}=10,10 \% \mathrm{G}-\mathrm{D}$ concentration, (B1) $\mathrm{N}=30,0 \%$ G-D concentration, (B2) $\mathrm{N}=30,10 \%$ G-D concentration. Surface densities of sulfonated PS and SiOH groups were kept constant at 1.0 groups $/ \mathrm{nm}^{2}$ and 2.8 groups $/ \mathrm{nm}^{2}$, respectively.

\section{TABLES}

Table S1. (D/G) surf and (G/D) surf molar ratios in the glycerol and dodecanol phases, respectively, on the NP surface as a function of the surface density of PS chains at variable sulfonation degree for $\mathrm{N}=30$ and a top distribution of sulfonic acid groups.

Table S2. (D/G) surf and (G/D) surf molar ratios in the glycerol and dodecanol phases, respectively, on the NP surface as a function of the G-D volume fraction at variable sulfonation degree for $\mathrm{N}=10$ and $\mathrm{N}=30$ and a top distribution of sulfonic acid groups. The surface density of sulfonated PS and $\mathrm{SiOH}$ groups was 1.0 groups $/ \mathrm{nm}^{2}$ and 2.8 groups $/ \mathrm{nm}^{2}$, respectively. 

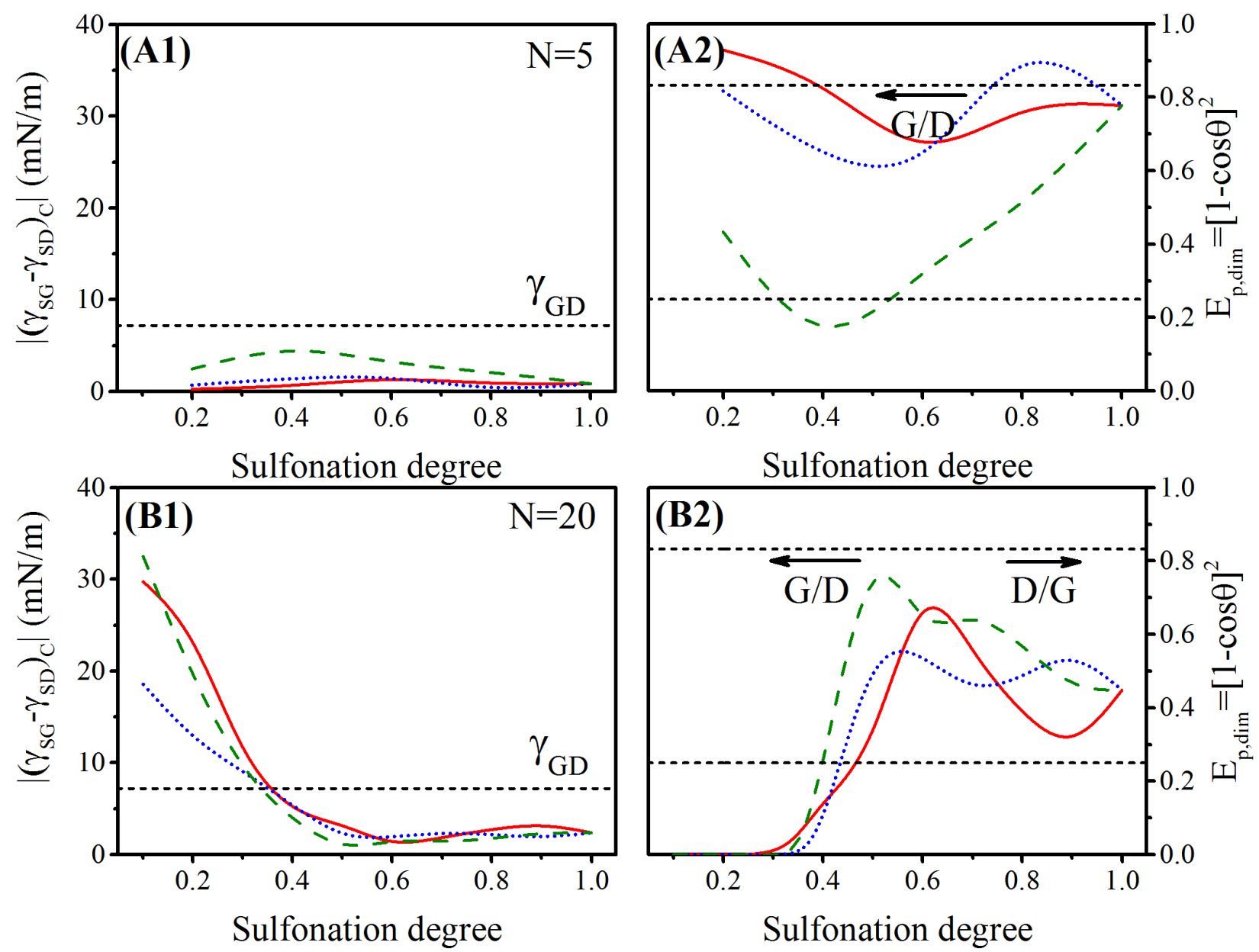

Figure S1. Evolution of $\left|\left(\gamma_{\mathrm{SG}}-\gamma_{\mathrm{SD}}\right)_{\mathrm{C}}\right|(\mathrm{A})$ and $\mathrm{E}_{\mathrm{p} \text {,dim }}(\mathrm{B})$ as a function of the sulfonation degree and distribution of sulfonic acid groups for a planar surface. Chain length: $\mathrm{N}=5$ (A1, A2) and $\mathrm{N}=20$ (B1, B2). The red-solid, blue-dotted and green-dashed curves refer to top, uniform and bottom distribution of sulfonic acid groups, respectively. Surface densities of sulfonated PS and $\mathrm{SiOH}$ groups were kept at 1.0 and 2.8 groups $/ \mathrm{nm}^{2}$, respectively. 


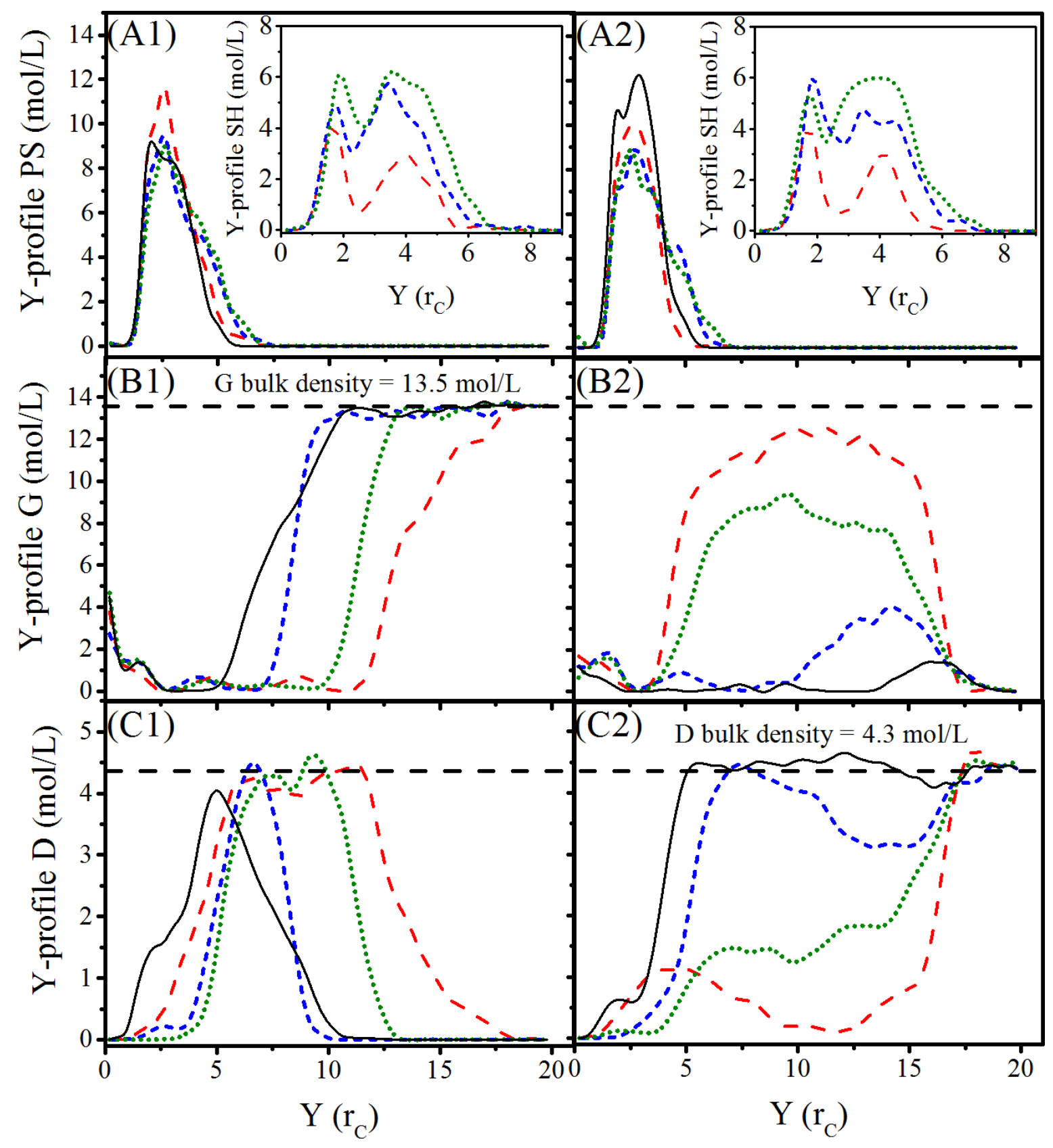

Figure S2. Local concentration profiles (Z-averaged) of (A) polystyrene (PS) and $\mathrm{SO}_{3} \mathrm{H}(\mathrm{SH})$ moieties, (B) G and (C) D along the Y-direction from the grafted SiNPs surface for the glycerol (A1, B1, C1) and dodecanol (A2, B2, C2) phases. NPs: N=10, top distribution of sulfonic acid groups, variable sulfonation degree at $0 \%$ (black-solid), 40\% (red-dashed), $80 \%$ (blue-dashed) and 100\% (green-dotted). Surface densities of sulfonated PS and $\mathrm{SiOH}$ groups were kept constant at 1.0 groups $/ \mathrm{nm}^{2}$ and 2.8 groups $/ \mathrm{nm}^{2}$, respectively. 


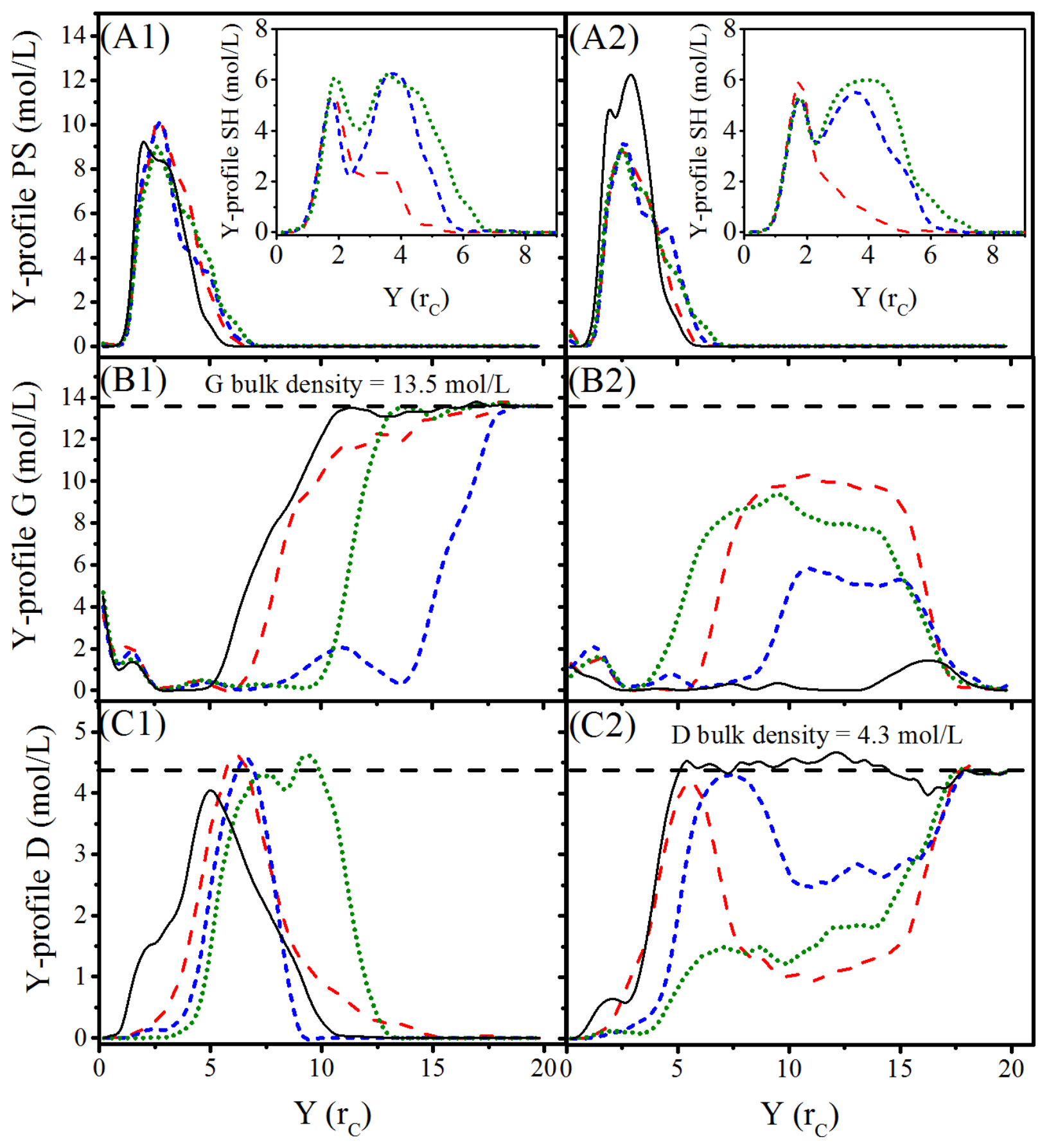

Figure S3. Local concentration profiles (Z-averaged) of (A) polystyrene (PS) and $\mathrm{SO}_{3} \mathrm{H}(\mathrm{SH})$ moieties, (B) G and (C) D along the Y-direction from the grafted NPs surface for the glycerol (A1, B1, C1) and dodecanol (A2, B2, C2) phases. NPs: N=10, bottom distribution of sulfonic acid groups, variable sulfonation degree at 0\% (black-solid), 40\% (red-dashed), 80\% (bluedashed) and 100\% (green-dotted). Surface densities of sulfonated PS and SiOH groups were kept constant at 1.0 groups $/ \mathrm{nm}^{2}$ and 2.8 groups $/ \mathrm{nm}^{2}$, respectively. 


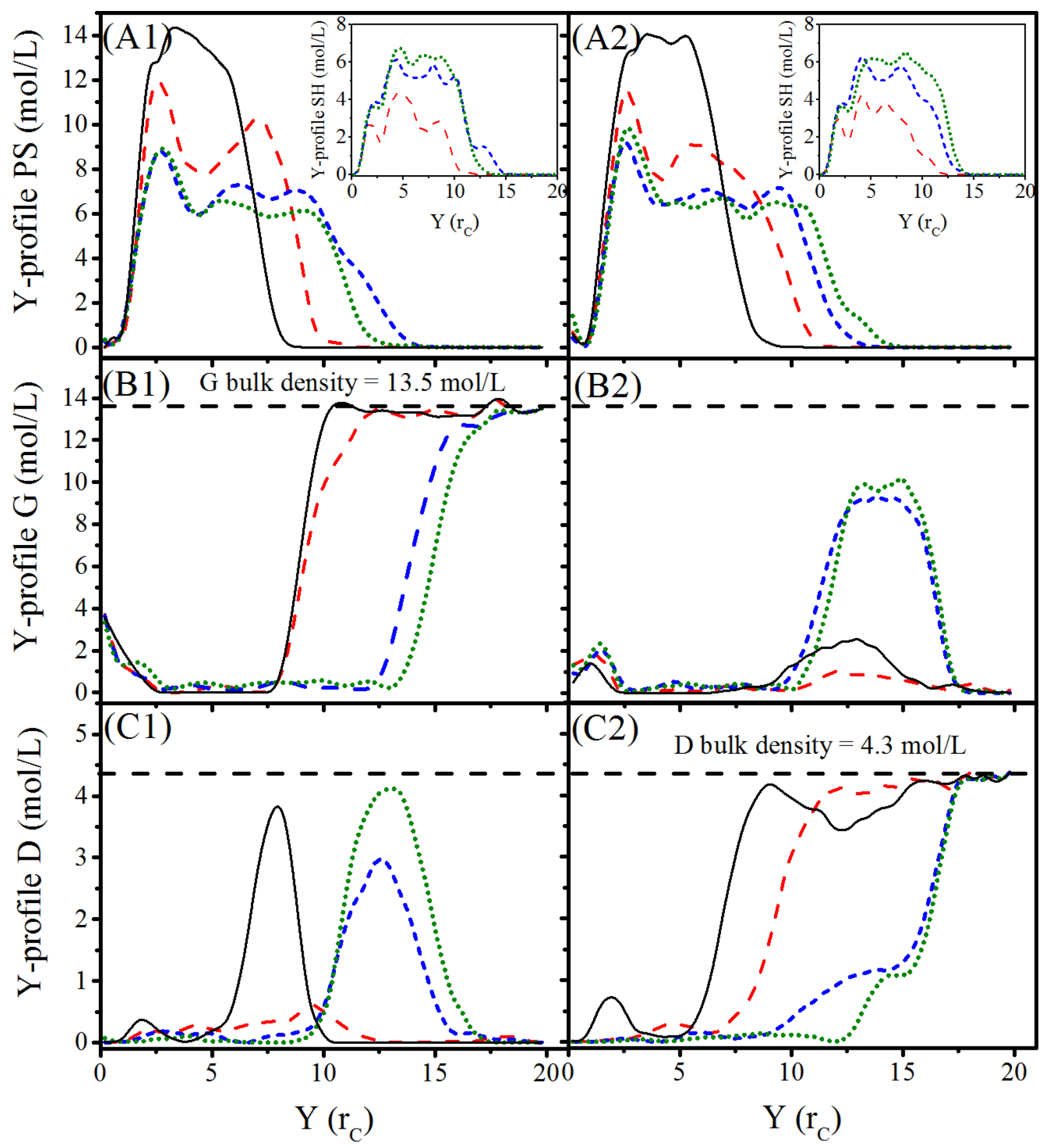

Figure S4. Local concentration profiles (Z-averaged) of (A) polystyrene (PS) and $\mathrm{SO}_{3} \mathrm{H}(\mathrm{SH})$ moieties, (B) G and (C) D along the Y-direction for the glycerol (A1, B1, C1) and dodecanol (A2, B2, C2) phases. NPs: $\mathrm{N}=30$, uniform distribution of sulfonic acid groups, variable sulfonation degree at 0\% (black-solid), 40\% (red-dashed), 80\% (blue-dashed) and 100\% (greendotted). Surface densities of sulfonated PS and $\mathrm{SiOH}$ groups were kept constant at 1.0 groups $/ \mathrm{nm}^{2}$ and 2.8 groups $/ \mathrm{nm}^{2}$, respectively. 


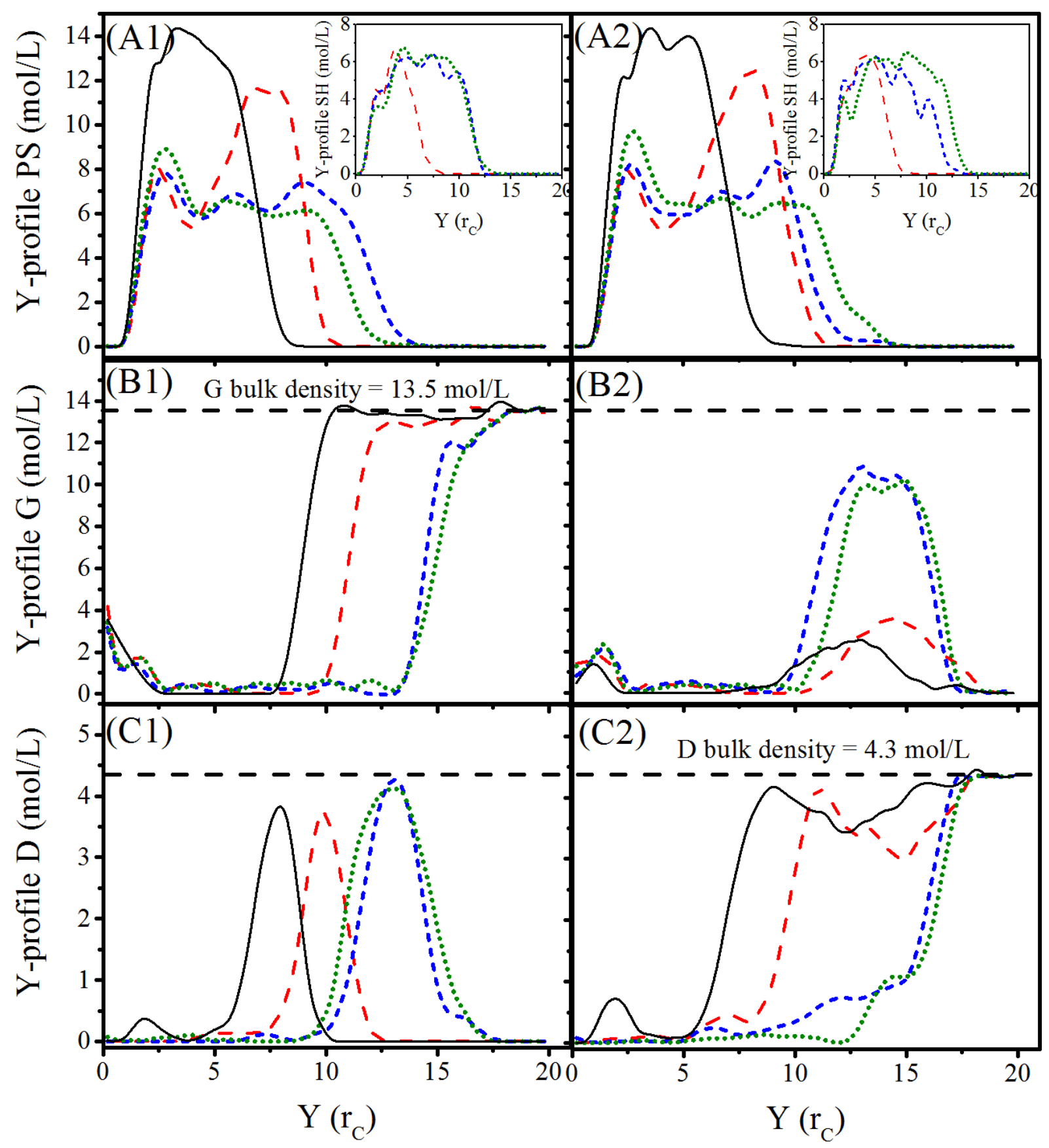

Figure S5. Local concentration profiles (Z-averaged) of (A) polystyrene (PS) and $\mathrm{SO}_{3} \mathrm{H}(\mathrm{SH})$ moieties, (B) G and (C) D along the Y-direction for the glycerol (A1, B1, C1) and dodecanol (A2, B2, C2) phases. NPs: N=30, bottom distribution of sulfonic acid groups, variable sulfonation degree at 0\% (black-solid), 40\% (red-dashed), 80\% (blue-dashed) and 100\% (greendotted). Surface densities of sulfonated PS and $\mathrm{SiOH}$ groups were kept constant at 1.0 groups $/ \mathrm{nm}^{2}$ and 2.8 groups $/ \mathrm{nm}^{2}$, respectively. 


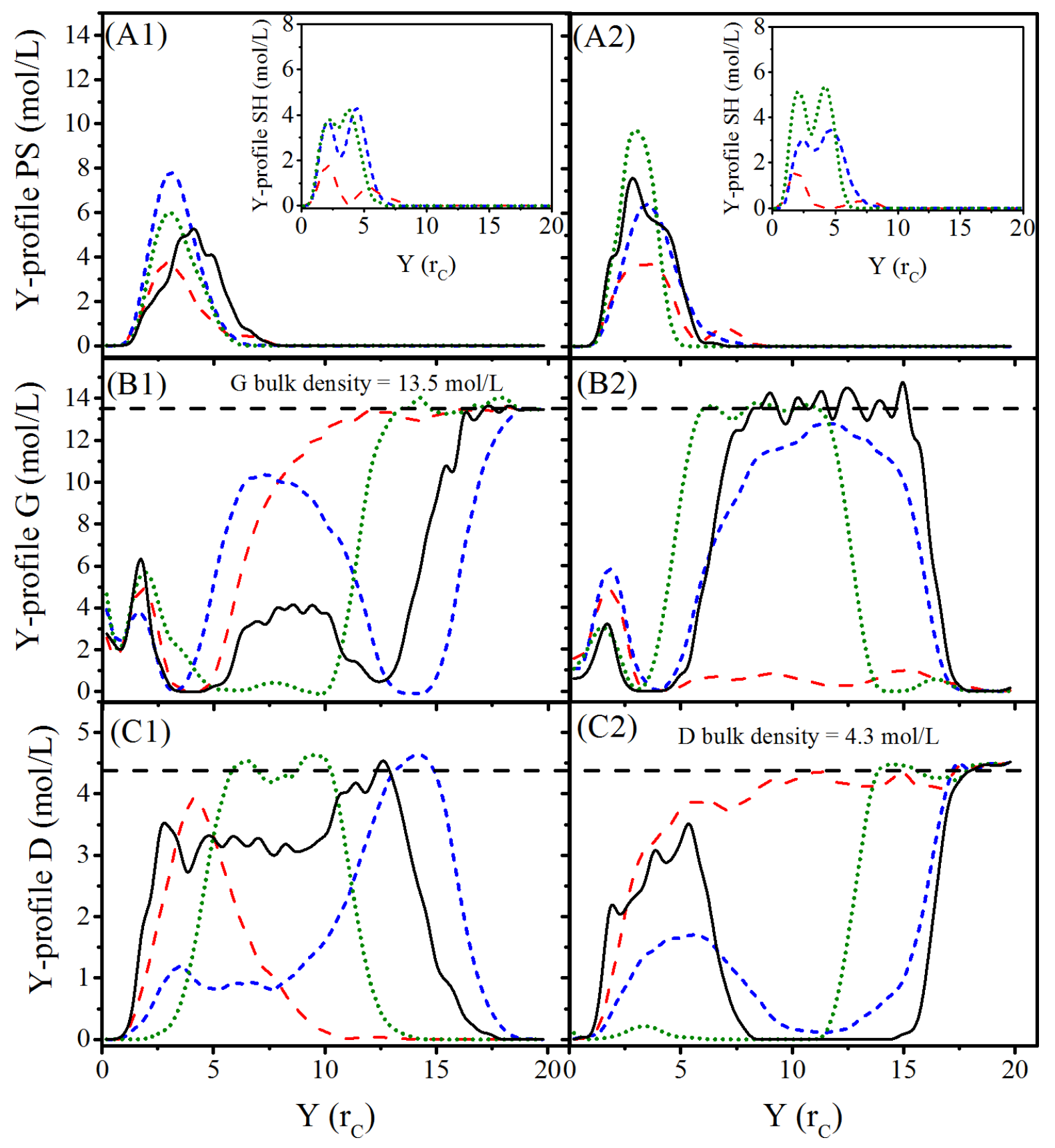

Figure S6. Local concentration profiles (Z-averaged) of (A) polystyrene (PS) and $\mathrm{SO}_{3} \mathrm{H}(\mathrm{SH})$ moieties, (B) $G$ and (C) D along the Y-direction for the glycerol (A1, B1, C1) and dodecanol (A2, B2, C2) phases. NPs: $\mathrm{N}=30$, top distribution of sulfonic acid groups, $0.25 \mathrm{PS}$ groups $/ \mathrm{nm}^{2}$, variable sulfonation degree at $0 \%$ (black-solid), $40 \%$ (red-dashed), $80 \%$ (blue-dashed) and 100\% (green-dotted). 


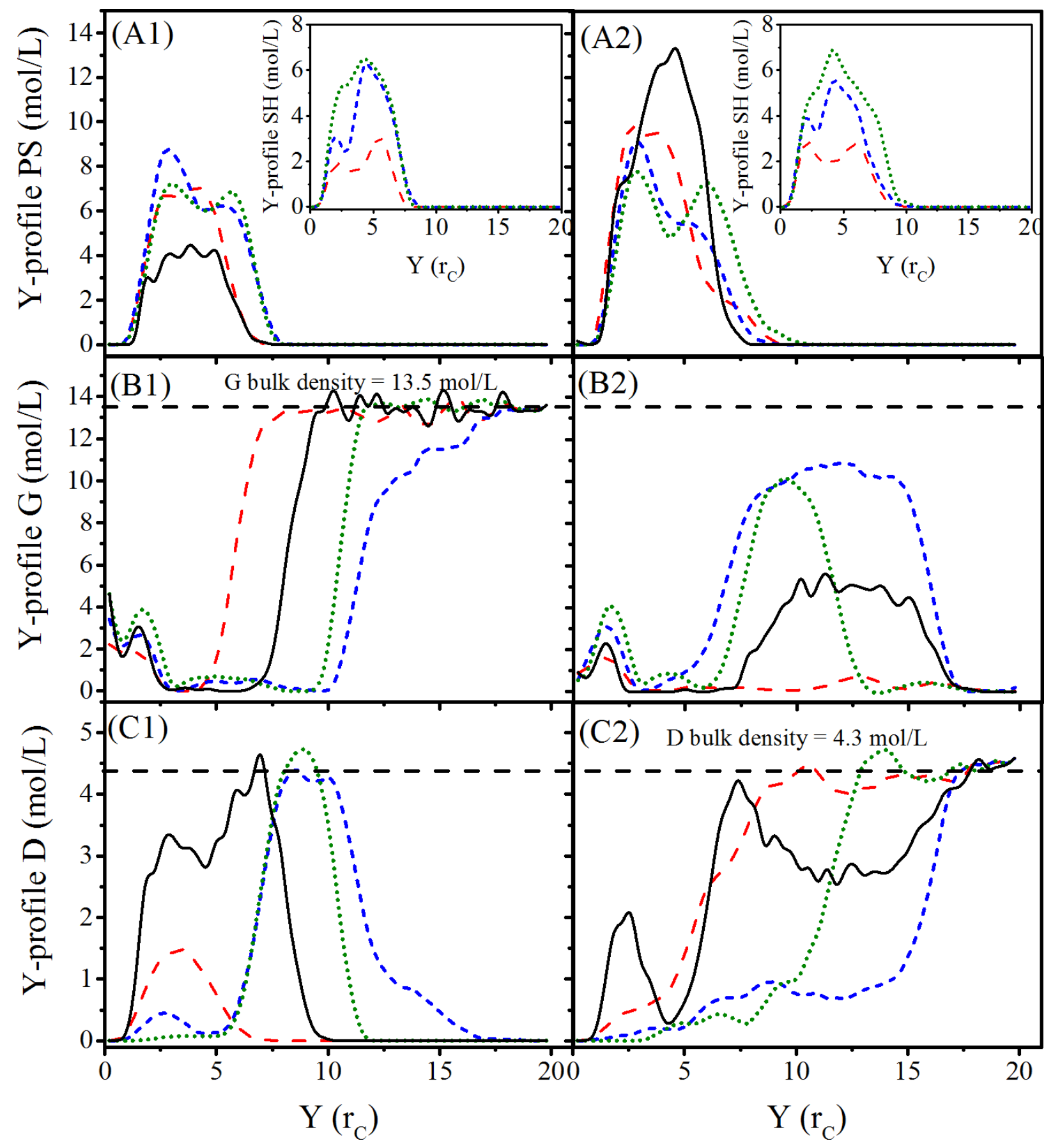

Figure S7. Local concentration profiles (Z-averaged) of (A) polystyrene (PS) and $\mathrm{SO}_{3} \mathrm{H}(\mathrm{SH})$ moieties, (B) G and (C) D along the Y-direction for the glycerol (A1, B1, C1) and dodecanol (A2, B2, C2) phases. NPs: $\mathrm{N}=30$, top distribution of sulfonic acid groups, 0.50 PS groups $/ \mathrm{nm}^{2}$, variable sulfonation degree at $0 \%$ (black-solid), $40 \%$ (red-dashed), $80 \%$ (blue-dashed) and 100\% (green-dotted). 


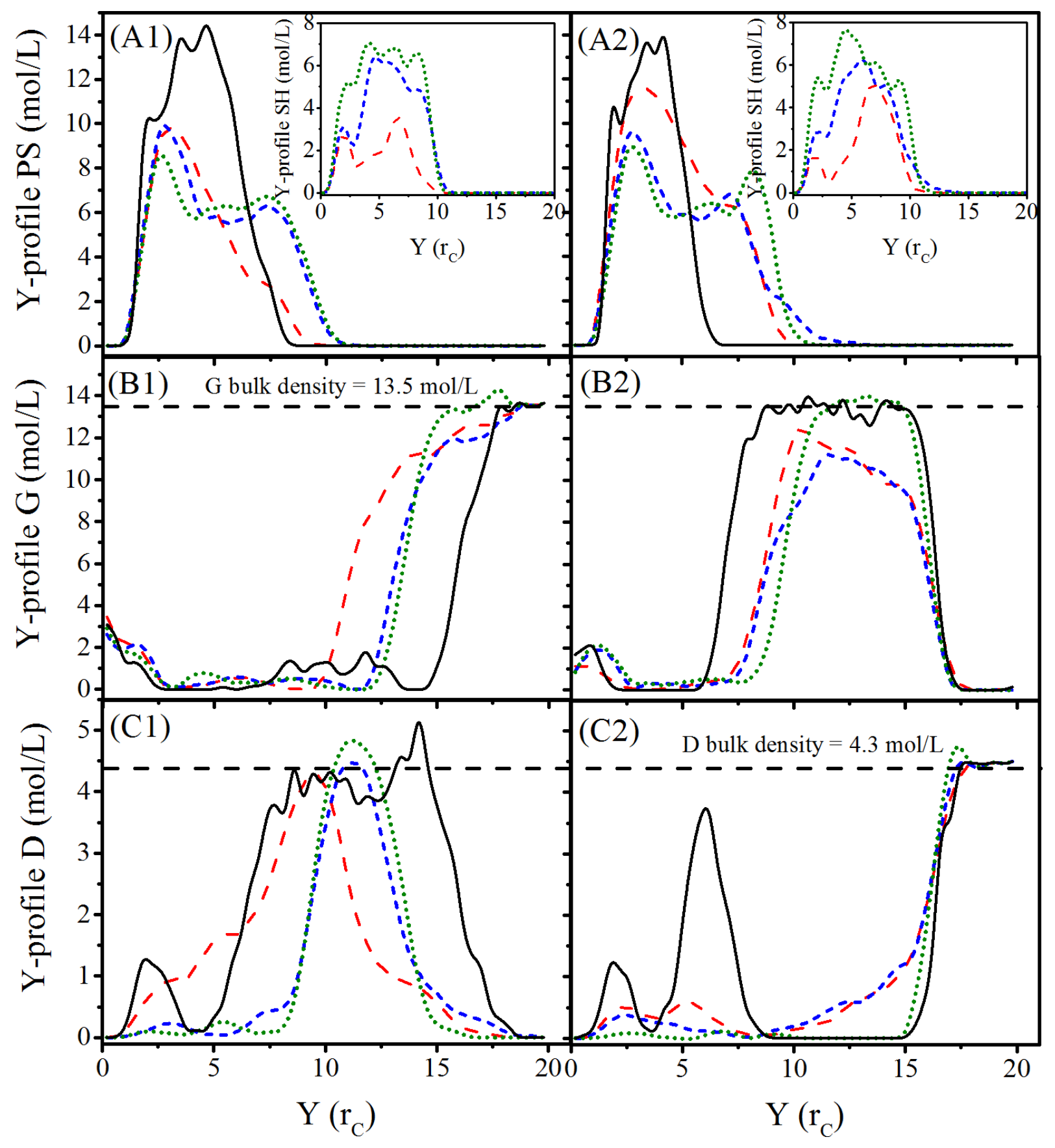

Figure S8. Local concentration profiles (Z-averaged) of (A) polystyrene (PS) and $\mathrm{SO}_{3} \mathrm{H}(\mathrm{SH})$ moieties, (B) G and (C) D along the Y-direction for the glycerol (A1, B1, C1) and dodecanol (A2, B2, C2) phases. NPs: $\mathrm{N}=30$, top distribution of sulfonic acid groups, $0.75 \mathrm{PS}$ groups $/ \mathrm{nm}^{2}$, variable sulfonation degree at $0 \%$ (black-solid), $40 \%$ (red-dashed), $80 \%$ (blue-dashed) and 100\% (green-dotted). 


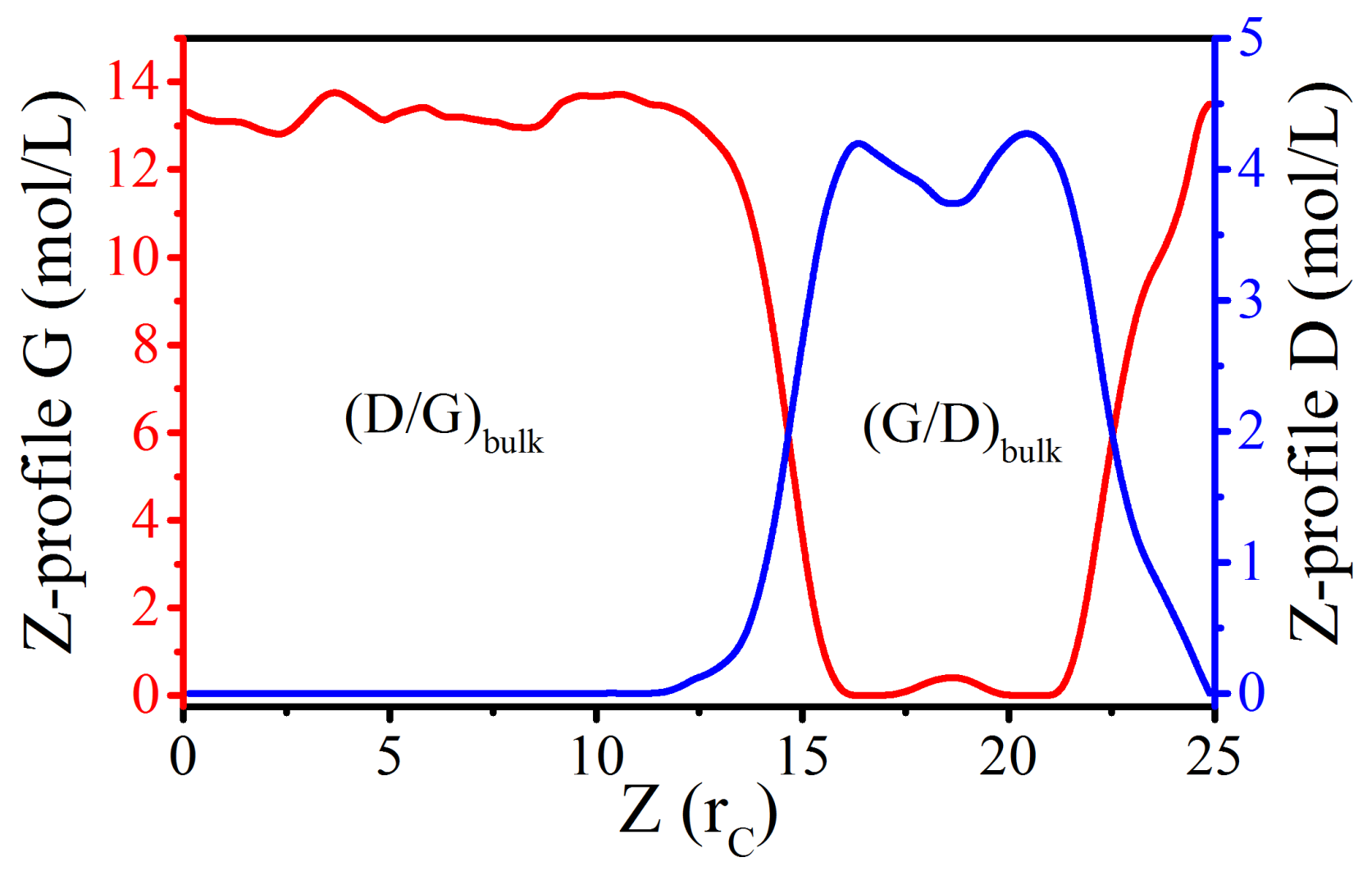

Figure S9. Local concentration profiles of G (red) and D (blue) in the bulk phase along the Zdirection. 

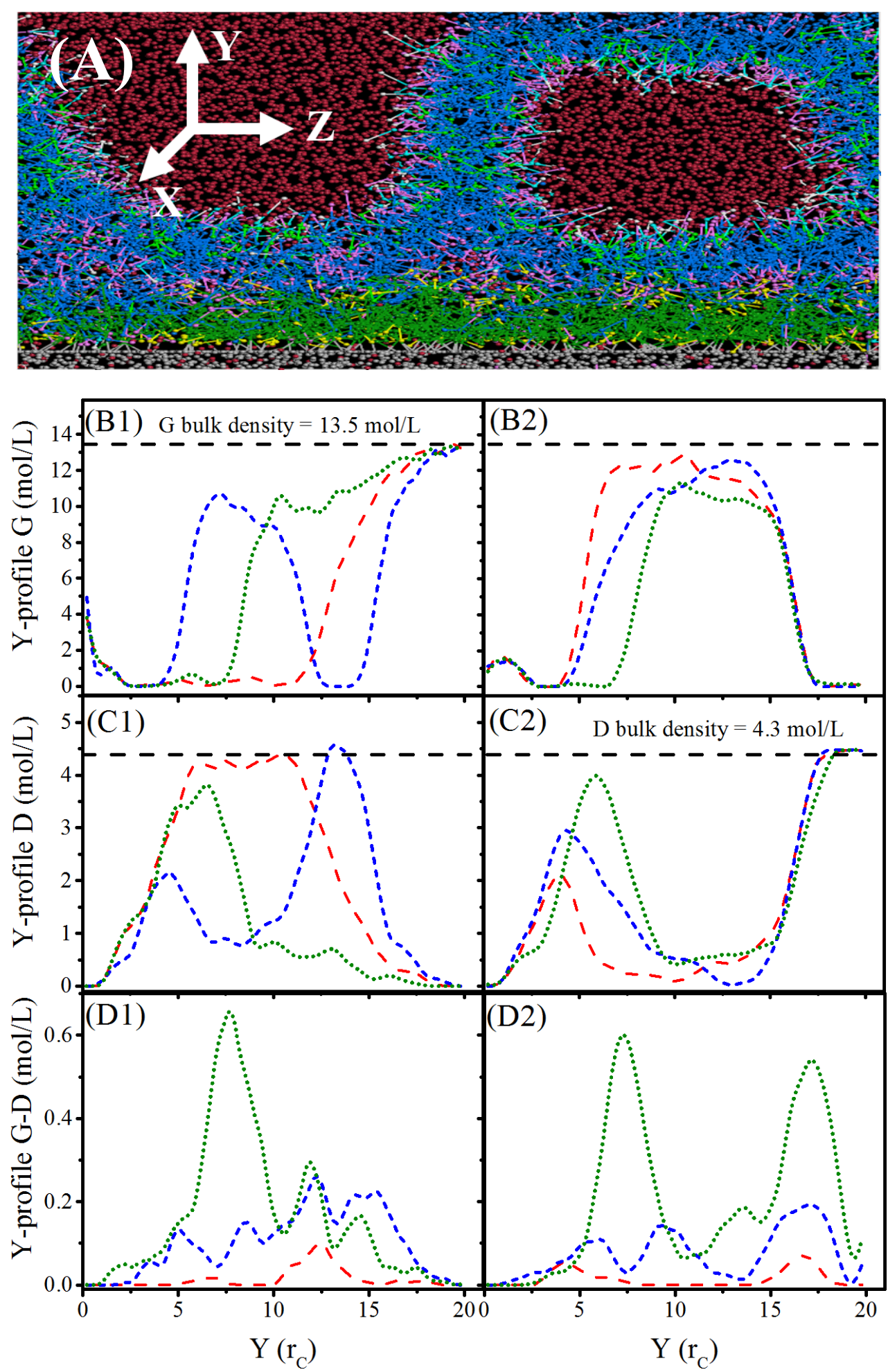

Figure S10. (A) Snapshot of the G (red), D (blue-pink) and G-D (bright green-bright blue) equilibrium distribution at the surface of a sulfonated PS-grafted NPs (PS, green; $\mathrm{SO}_{3} \mathrm{H}$, yellow); Local concentration profiles (Z-averaged) of (A) G, (B) D and (C) G-D along the Y-direction for the glycerol (A1, B1, C1) and dodecanol (A2, B2, C2) phases at variable G-D concentration of 1\% (red-dashed) and 5\% (blue-dashed) and 10\% (green-dotted). NPs: N=10, top distribution of sulfonic acid groups, 20\% sulfonation degree. Surface densities of sulfonated PS and $\mathrm{SiOH}$ groups were kept constant at 1.0 groups $/ \mathrm{nm}^{2}$ and 2.8 groups $/ \mathrm{nm}^{2}$, respectively. 


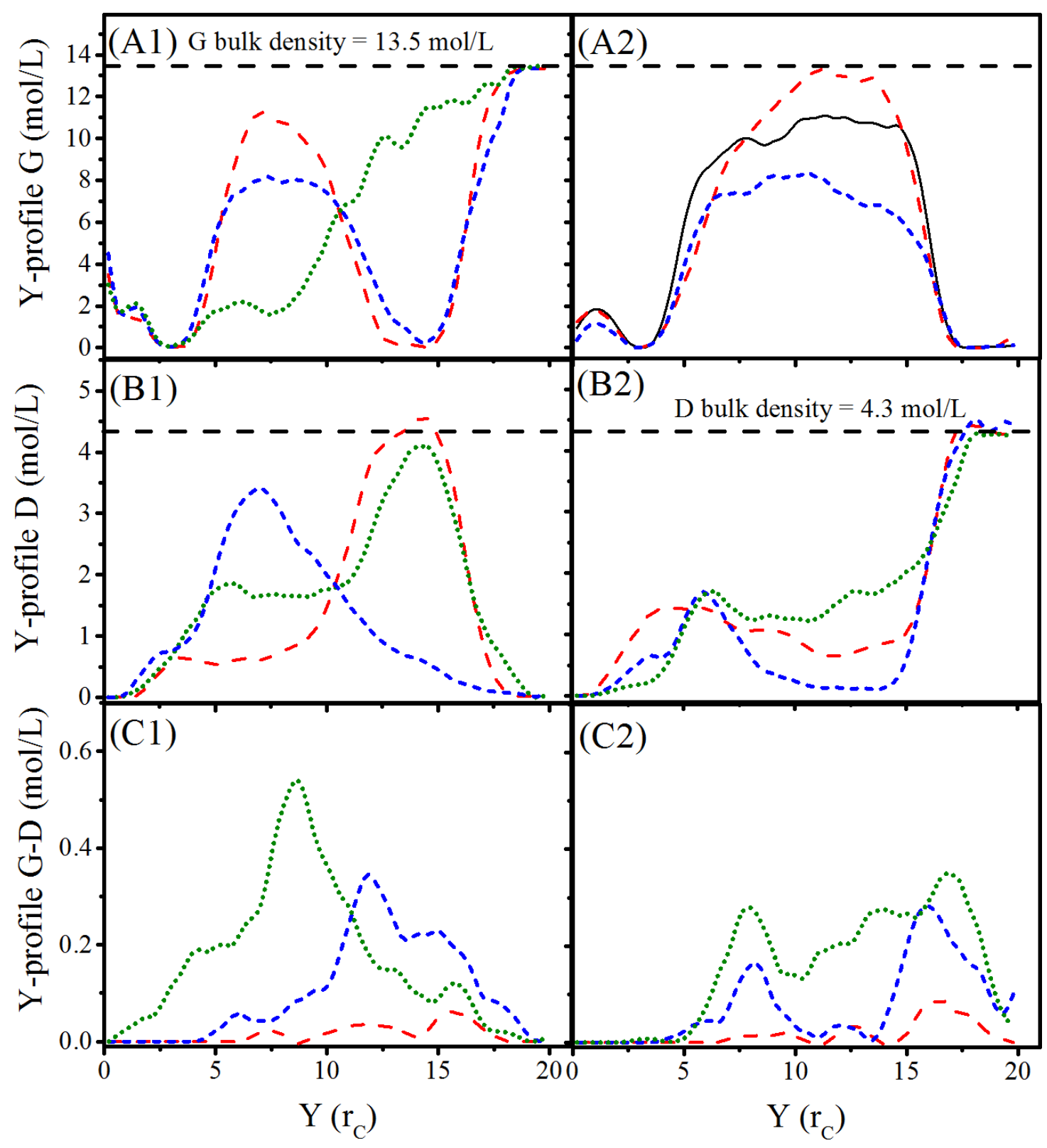

Figure S11. Local concentration profiles (Z-averaged) of (A) G, (B) D and (C) G-D along the Ydirection for the glycerol (A1, B1, C1) and dodecanol (A2, B2, C2) phases at variable G-D concentration of $1 \%$ (red-dashed) and 5\% (blue-dashed) and 10\% (green-dotted). NPs: N=10, top distribution of sulfonic acid groups, $60 \%$ sulfonation degree. Surface densities of sulfonated PS and $\mathrm{SiOH}$ groups were kept constant at 1.0 groups $/ \mathrm{nm}^{2}$ and 2.8 groups $/ \mathrm{nm}^{2}$, respectively. 

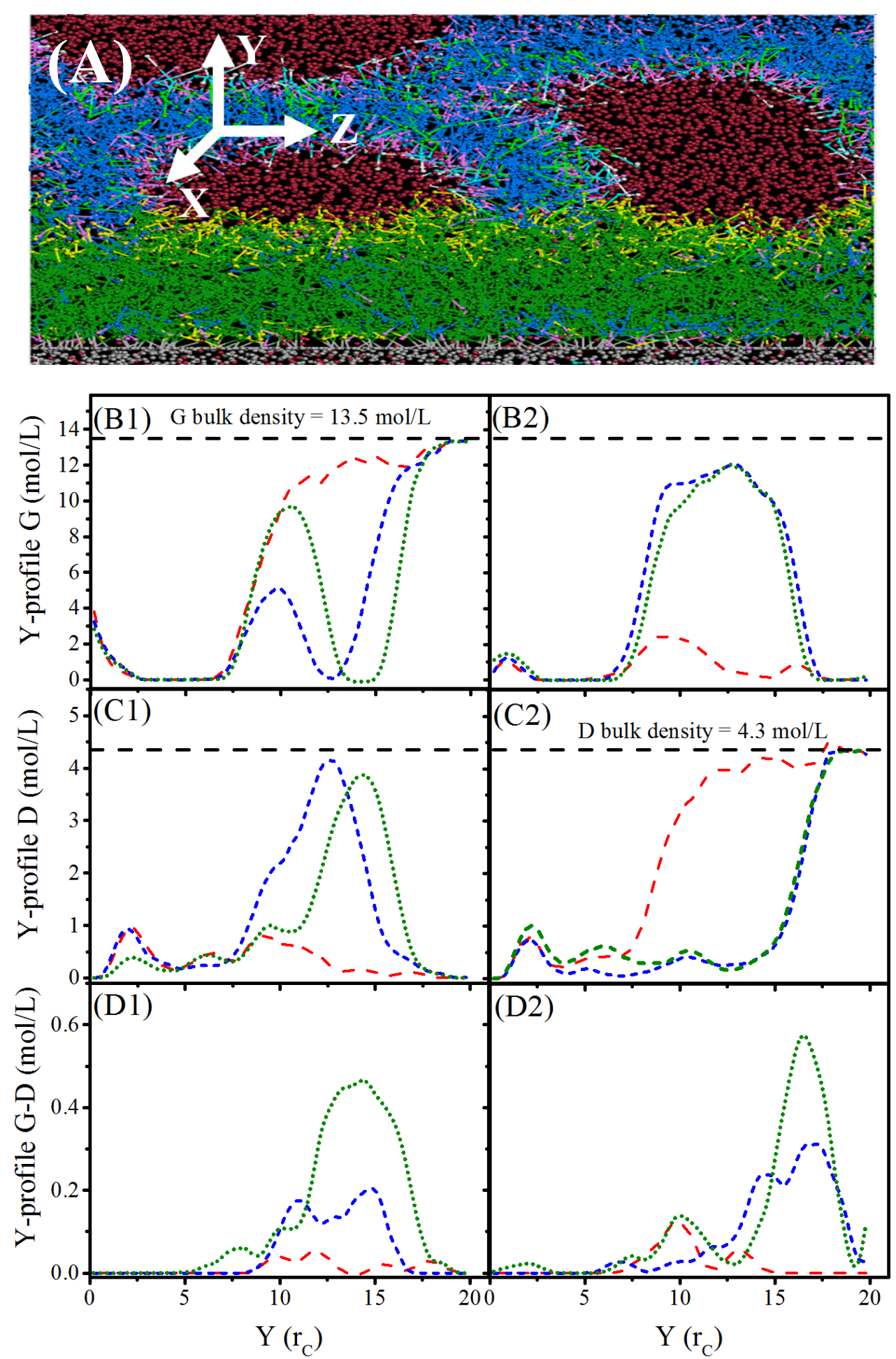

Figure S12. (A) Snapshot of the G (red), D (blue-pink) and G-D (bright green-bright blue) equilibrium distribution at the surface of a sulfonated PS-grafted NPs (PS, green; $\mathrm{SO}_{3} \mathrm{H}$, yellow); Local concentration profiles (Z-averaged) of (A) G, (B) D and (C) G-D along the Y-direction for the glycerol (A1, B1, C1) and dodecanol (A2, B2, C2) phases at variable G-D concentration of 1\% (red-dashed) and 5\% (blue-dashed) and 10\% (green-dotted). NPs: N=30, top distribution of sulfonic acid groups, 20\% sulfonation degree. Surface densities of sulfonated PS and $\mathrm{SiOH}$ groups were kept constant at 1.0 groups $/ \mathrm{nm}^{2}$ and 2.8 groups $/ \mathrm{nm}^{2}$, respectively. 


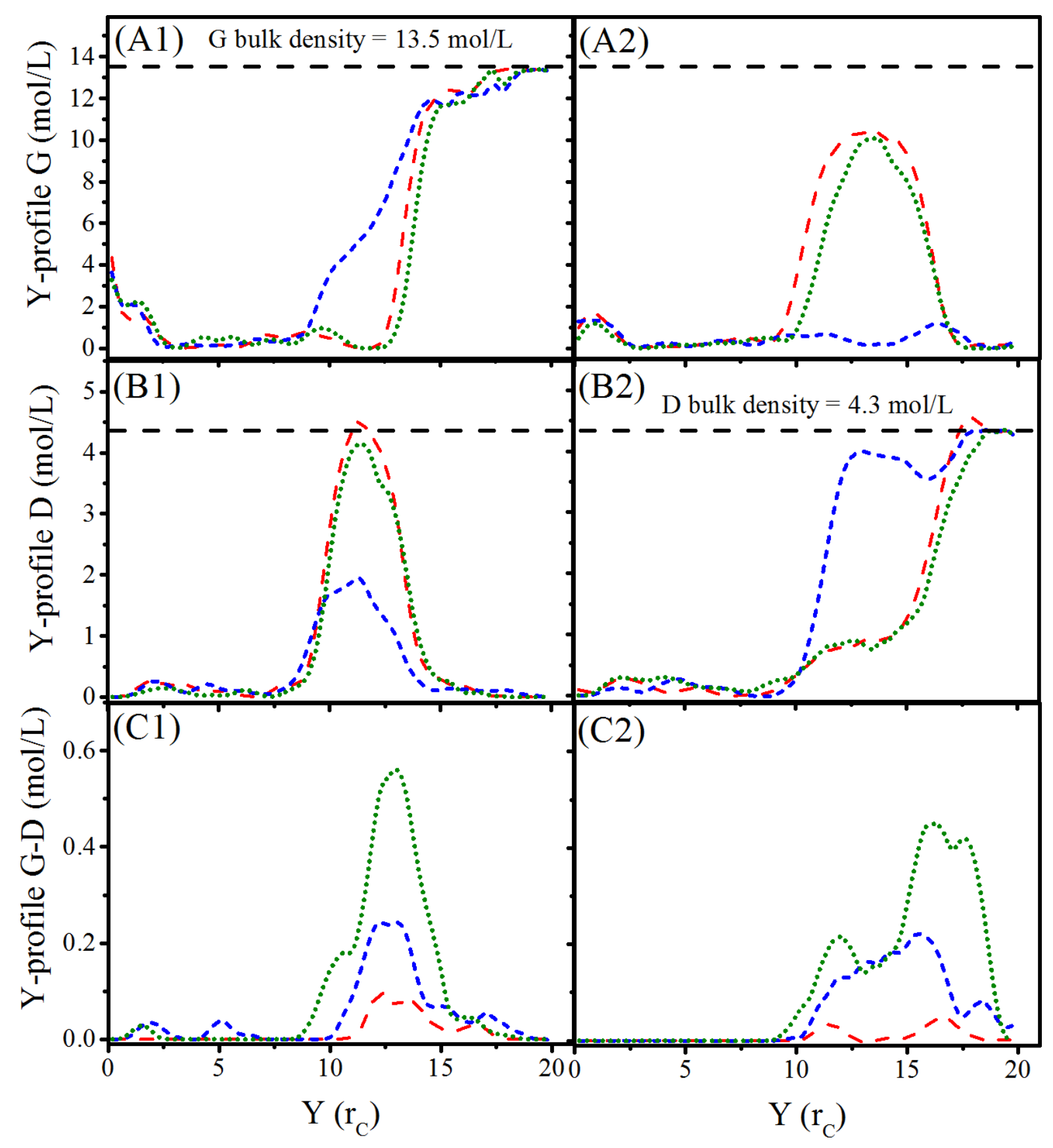

Figure S13. Local concentration profiles (Z-averaged) of (A) G, (B) D and (C) G-D along the Ydirection for the glycerol (A1, B1, C1) and dodecanol (A2, B2, C2) phases at variable G-D concentration of $1 \%$ (red-dashed) and 5\% (blue-dashed) and 10\% (green-dotted). NPs: N=30, top distribution of sulfonic acid groups, $60 \%$ sulfonation degree. Surface densities of sulfonated PS and $\mathrm{SiOH}$ groups were kept constant at 1.0 groups $/ \mathrm{nm}^{2}$ and 2.8 groups $/ \mathrm{nm}^{2}$, respectively. 

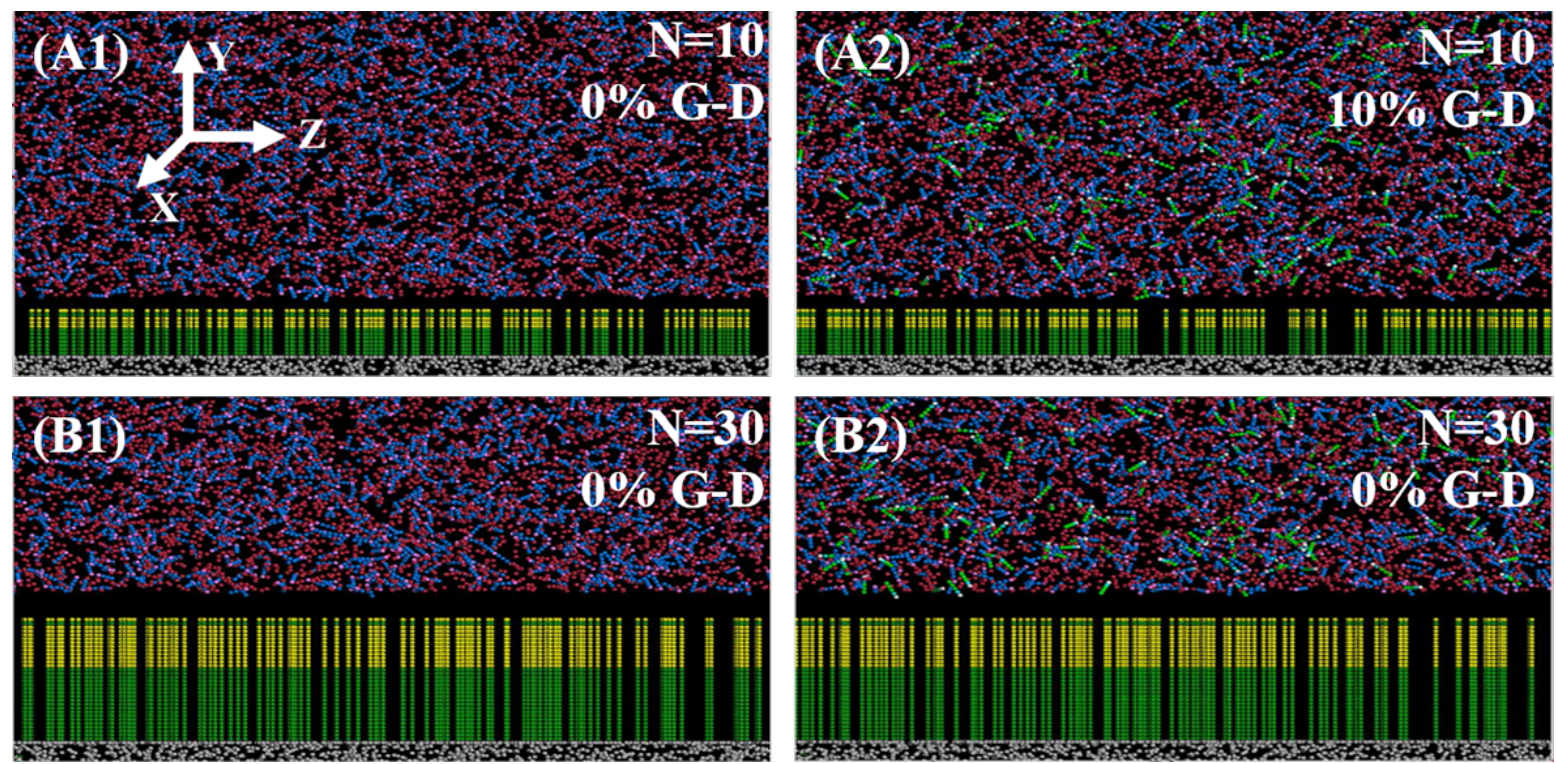

Figure S14. Snapshot of the G (red), D (blue-pink) and G-D (bright green-bright blue) initial distribution at the surface of a sulfonated PS-grafted NPs (PS, green; $\mathrm{SO}_{3} \mathrm{H}$, yellow) with $40 \%$ sulfonation degree and top distribution of sulfonic acid groups. (A1) $\mathrm{N}=10,0 \% \mathrm{G}-\mathrm{D}$ concentration, (A2) $\mathrm{N}=10,10 \% \mathrm{G}-\mathrm{D}$ concentration, (B1) $\mathrm{N}=30,0 \% \mathrm{G}-\mathrm{D}$ concentration, (B2) $\mathrm{N}=30,10 \% \mathrm{G}-\mathrm{D}$ concentration. Surface densities of sulfonated PS and $\mathrm{SiOH}$ groups were kept constant at 1.0 groups $/ \mathrm{nm}^{2}$ and 2.8 groups $/ \mathrm{nm}^{2}$, respectively. 
Table S1. (D/G) surf and (G/D) surf molar ratios in the glycerol and dodecanol phases, respectively, on the NP surface as a function of the surface density of PS chains at variable sulfonation degree for $\mathrm{N}=30$ and a top distribution of sulfonic acid groups

\begin{tabular}{cccccc|cccc}
\hline \multirow{2}{*}{ N (-) } & $\begin{array}{c}\text { Sulfonation } \\
\text { degree (\%) }\end{array}$ & \multicolumn{3}{c|}{ Glycerol phase $-(\mathrm{D} / \mathrm{G})_{\text {surf }}$} & \multicolumn{4}{c}{ Dodecanol phase $-(\mathrm{G} / \mathrm{D})_{\text {surf }}$} \\
\cline { 2 - 10 } & 0.25 & 0.50 & 0.75 & 1.00 & 0.25 & 0.50 & 0.75 & 1.00 \\
\cline { 2 - 10 } & $20 \%$ & 0.41 & 2.66 & 2.77 & 2.90 & 2.87 & 4.93 & 4.04 & 5.71 \\
& $40 \%$ & 0.41 & 0.17 & 2.62 & 2.48 & 0.46 & 0.27 & 6.02 & 22.6 \\
30 & $60 \%$ & 0.08 & 2.88 & 2.15 & 0.06 & 1.30 & 9.71 & 6.36 & 0.54 \\
& $80 \%$ & 0.34 & 1.44 & 1.13 & 0.59 & 4.67 & 8.80 & 12.6 & 13.5 \\
& $100 \%$ & 1.03 & 0.62 & 1.21 & 1.48 & 3.71 & 10.2 & 5.42 & 15.2 \\
\hline
\end{tabular}


Table S2. (D/G) surf and (G/D) surf molar ratios in the glycerol and dodecanol phases, respectively, on the NP surface as a function of the G-D volume fraction at variable sulfonation degree for $\mathrm{N}=10$ and $\mathrm{N}=30$ and a top distribution of sulfonic acid groups. The surface density of sulfonated PS and $\mathrm{SiOH}$ groups was 1.0 groups $/ \mathrm{nm}^{2}$ and 2.8 groups $/ \mathrm{nm}^{2}$, respectively.

\begin{tabular}{|c|c|c|c|c|c|c|c|}
\hline \multirow{3}{*}{$\mathrm{N}(-)$} & \multirow{3}{*}{$\begin{array}{c}\text { G-D } \\
\text { concentration } \\
(\text { vol. } \%)\end{array}$} & \multirow{2}{*}{\multicolumn{3}{|c|}{$\begin{array}{c}\text { Glycerol phase }-(\mathrm{D} / \mathrm{G})_{\text {surf }} \\
\text { Sulfonation degree }(\%)\end{array}$}} & \multirow{2}{*}{\multicolumn{3}{|c|}{$\begin{array}{c}\text { Dodecanol phase }-(\mathrm{G} / \mathrm{D})_{\text {surf }} \\
\text { Sulfonation degree }(\%)\end{array}$}} \\
\hline & & & & & & & \\
\hline & & $20 \%$ & $40 \%$ & $60 \%$ & $20 \%$ & $40 \%$ & $60 \%$ \\
\hline \multirow{3}{*}{10} & $1 \%$ & 6.02 & 0.68 & 0.12 & 4.94 & 0.28 & 3.48 \\
\hline & $5 \%$ & 0.23 & 2.21 & 0.30 & 1.64 & 4.22 & 3.47 \\
\hline & $10 \%$ & 0.43 & 2.22 & 0.98 & 0.31 & 7.31 & 3.93 \\
\hline \multirow{3}{*}{30} & $1 \%$ & 0.15 & 2.29 & 1.54 & 0.85 & 9.30 & 9.92 \\
\hline & $5 \%$ & 0.62 & 0.42 & 0.37 & 13.8 & 15.8 & 0.71 \\
\hline & $10 \%$ & 0.17 & 0.55 & 1.06 & 5.74 & 11.6 & 5.28 \\
\hline
\end{tabular}

